\title{
Development of the PC-7, a Quantifiable Assessment of Spiritual Concerns of Patients Receiving Palliative Care Near the End of Life
}

\author{
George Fitchett, DMin, PhD, ${ }^{1}$ Anna Lee Hisey Pierson, MDiv, ${ }^{2}$ Christine Hoffmeyer, MDiv, ${ }^{3}$ \\ Dirk Labuschagne, MDiv, ${ }^{4}$ Aoife Lee, DMin, ${ }^{5}$ Stacie Levine, MD, ${ }^{6}$ Sean O'Mahony, MB, BCh, BAO, \\ Karen Pugliese, $\mathrm{MA}^{8}$, and Nancy Waite, MDiv, $\mathrm{PhD}^{9}$
}

\begin{abstract}
Background: Attending to the religious/spiritual (R/S) concerns of patients is a core component of palliative care. A primary responsibility of the chaplain is to conduct a thorough assessment of palliative care patients' R/S needs and resources. Problems with current approaches to spiritual assessment in all clinical contexts, including palliative care, include limited evidence for their validity, reliability, or clinical usefulness; narrative content; and lack of clinical specificity.

Objectives: The aim of our work was to develop an evidence-based, quantifiable model for the assessment of unmet spiritual concerns of palliative care patients near the end of life.

Design: The PC-7 model was developed by a team of chaplains working in palliative care. Phase 1 used literature in the field and the chaplains' clinical practice to identify key concerns in the spiritual care of palliative care patients. Phase 2 focused on developing indicators of those concerns and reliability in the chaplains' rating of them. Results: Key concerns in the model include the following. Need for meaning in the face of suffering; need for integrity, a legacy; concerns about relationships; concern or fear about dying or death; issues related to treatment decision making; R/S struggle; and other concerns. An approach to scoring the patients' degree of unmet spiritual concerns was adapted from the literature. Assessing cases from the chaplains' practice led to high levels of agreement (reliability).

Conclusion: Using the PC-7 model, chaplains can describe and quantify the key spiritual concerns of palliative care patients. Further research is needed to test its validity, reliability, and clinical usefulness.
\end{abstract}

Keywords: chaplain care; palliative care; spiritual assessment; spiritual care

\section{Introduction}

$\mathbf{T}$ HE IMPORTANCE of attending to religious and spiritual concerns in palliative care is widely recognized in practice guidelines and consensus statements. ${ }^{1}$ It is also generally recognized that chaplains are the spiritual care specialists on the palliative care team, and one of their primary responsibilities is conducting assessments of the patients' religious/spiritual (R/S) needs and existing resources. ${ }^{2}$ While the limitations of chaplains' documentation of their spiritual assessments have been described, ${ }^{3-5}$ the limitations of current approaches to spiritual assessment have received only brief attention. ${ }^{6}$

Current approaches to spiritual assessment in all clinical contexts, not just palliative care, are marked by three major

\footnotetext{
${ }^{1}$ Department of Religion, Health, and Human Values, Rush University Medical Center, Chicago, Illinois.

${ }^{2}$ Advocate Aurora Good Samaritan Hospital, Downers Grove, Illinois.

${ }^{3}$ Advocate Aurora Lutheran General Hospital, Park Ridge, Illinois.

${ }^{4}$ Department of Religion, Health, and Human Values, Rush University Medical Center, Chicago, Illinois.

${ }^{5}$ Spiritual Care, Rush Oak Park Hospital, Oak Park, Illinois.

${ }^{6}$ Section of Geriatrics and Palliative Medicine, Department of Medicine, University of Chicago Medicine, Chicago, Illinois.

${ }^{7}$ Section of Palliative Medicine, Department of Internal Medicine, Rush University Medical Center, Chicago, Illinois.

${ }^{8}$ Spiritual Care and Education, Northwestern Medicine, Central DuPage Hospital, Winfield, Illinois.

${ }^{9}$ Evanston Hospital, NorthShore University Health System, Evanston, Illinois.

Accepted August 8, 2019.
}

(C) George Fitchett et al., 2019; Published by Mary Ann Liebert, Inc. This Open Access article is distributed under the terms of the Creative Commons Attribution Noncommercial License (http://creativecommons.org/licenses/by-nc/4.0/) which permits any noncommercial use, distribution, and reproduction in any medium, provided the original author(s) and the source are credited. 
limitations. The first is that, with few exceptions, most published models for spiritual assessment were designed to be used in multiple clinical contexts - what we call the "one-sizefits-all" approach. ${ }^{7-10}$ These models were developed before the growth of research about R/S issues associated with different clinical conditions, for example, oncology. ${ }^{11,12} \mathrm{Re}-$ search now permits the development of more efficient and research-informed condition-specific models for spiritual assessment. This includes spiritual assessment in palliative care focused on the spiritual concerns of these patients who have been identified through research. ${ }^{6}$

The second limitation is that most models for spiritual assessment are based on narrative. Many chaplains prefer a "conversational approach" to spiritual assessment and have been uncomfortable with models that "attempt to measure or quantify spirituality, religiosity, or spiritual injury.",13(p5) Because it is essential that chaplains develop the ability to describe the effects (outcomes) of their care, ${ }^{14}$ models for spiritual assessment must have a quantitative component, which could be combined with narrative summaries. The Spiritual Distress Assessment Tool (SDAT), developed by Monod and colleagues, ${ }^{15}$ demonstrates that a quantifiable approach to assessing unmet spiritual needs is possible.

The third limitation is the lack of a standard, evidence-based approach to spiritual assessment in palliative care or in any clinical context. The existing evidence is limited, but it suggests that most chaplains use their own model for spiritual assessment or a model developed in their local spiritual care department. ${ }^{16}$ Thus, at best, the level of evidence supporting most models for spiritual assessment is expert opinion. The lack of evidence-based models for spiritual assessment raises questions about the quality of this central spiritual care activity. This lack of standardization makes it harder for clinical colleagues to understand the R/S dimension of the patient's experience and why it may be relevant for the patient's overall care. It also limits the research that can be conducted about spiritual assessment and spiritual care.

The aim of this project was to develop an evidence-based model for spiritual assessment, specific to adult palliative care, that quantified the patients' level of unmet spiritual concerns and that could be widely adopted.

\section{Methods}

The project was carried out by a team of seven Chicago-area chaplains working in different institutions in palliative care and related areas (e.g., intensive care units, chaplaincy research). Some team members were relatively new to chaplaincy and palliative care (one to two years of experience); others were experienced palliative care spiritual care providers and leaders in the development of specialty certification in palliative care for chaplains. The team came together as part of a multiyear palliative care education initiative, The Coleman Palliative Medicine Training Program. ${ }^{17}$

There were two phases in the development of the PC-7 model for spiritual assessment in palliative care. The first phase focused on identifying a set of key themes or central spiritual issues and related indicators for patients receiving palliative care. The themes and indicators were generated from a review of relevant literature, from a series of case discussions, and from the clinical experience of the team members. The second phase focused on developing inter- rater reliability in using the model to score patients' unmet spiritual needs. This was accomplished through monthly discussions of case studies provided by members of the team.

Chaplains working in palliative care address a wide variety of concerns of both patients and their loved ones. ${ }^{18,19}$ The team felt that, for our initial effort, it was unrealistic to develop a model for spiritual assessment that addressed all of these situations; therefore, we developed a model for spiritual assessment that focused only on the patient who was receiving palliative care. Although family members are often the focus of a palliative care chaplains' attention, the model does not focus on assessing the spiritual needs of family members. It was further decided that the model would focus only on palliative care patients who were near the end of life (e.g., patients facing decisions about discontinuing curative treatment); themes were not developed for all patients who receive palliative care consultation (e.g., patients being seen for pain control who are not near the end of life).

\section{Results}

\section{Developing the themes and indicators}

Our initial spiritual assessment model contained five themes. Four of the themes came from the work of Steinhauser and colleagues on quality of life at the end of life. That team's investigations began with qualitative interviews in which patients with advanced illness were asked to describe factors associated with a good death. ${ }^{20}$ Those accounts were used to develop an initial version of the QUAL-E, an instrument designed to assess quality of life at the end of life for patients with advanced illness. ${ }^{21}$ Further psychometric testing of the QUAL-E ${ }^{22}$ identified four domains, two of which-life completion and preparation for the end of life-we found to be relevant for our work. Four of the initial themes in our spiritual assessment model were derived from items assessing these domains. They were Need for Meaning, Need for a Legacy, Concerns about Family, and Fear about Dying. We added a fifth theme, R/S Struggle, based on the work of Pargament and colleagues ${ }^{23}$ and the evidence about the prevalence and harmful effects of R/S struggle or R/S pain. ${ }^{24,25}$

In each monthly conference call, we used the most current version of the model, updated after each call to reflect consensus about alterations, to assess a case brought by a member of the team. A total of 14 patients were discussed; they included men and women, middle age and older, white and African American, and most reporting a Christian religious affiliation. All of these were hospitalized patients with advanced illness who had been referred for palliative care and assistance in planning goals of care.

In early discussions, we realized the similarity between two of our themes and the stages of adult and late life development in the work of Erik Erikson. ${ }^{26}$ Specifically, the theme Need for Meaning was related to Erikson's description of Integrity, and the theme Need for Legacy was related to Erikson's description of Generativity. We also realized the similarity between our theme Need for Meaning and Elizabeth MacKinley's description of the spiritual tasks of aging. ${ }^{27}$ These monthly case discussions also led to the addition of one more theme, Issues Related to Making Decisions about Treatment. We also added a theme for Other Dimensions of Spiritual Concern that were not encompassed in the other themes. 
Our team discussions led to the elaboration of the indicators for each theme. The indicators serve to clarify the kinds of $\mathrm{R} / \mathrm{S}$ concerns that are part of each theme. The indicators also include notes that differentiate apparently similar R/S concerns so that the chaplain does not give a score to more than one theme for any particular patient's R/S concern. There have been 11 iterations of our model for spiritual assessment; many iterations only had minor revisions to the indicators. Table 1 shows the current model.

\section{Scoring unmet spiritual concerns}

We adopted the approach to scoring unmet R/S concerns or needs from the SDAT developed by Monod and colleagues. $^{15,28}$ The SDAT was developed for use in geriatric medical rehabilitation; it uses five themes identified by Monod and colleagues for that context. ${ }^{29}$ As we have described, we developed seven different themes that were relevant for our clinical focus, care for patients receiving

Table 1. Chaplain Assessment of Explicit Spiritual Concerns of Patients in Palliative Care

Indicators (these indicators are meant to be suggestive
Theme
not exhaustive of the associated themes)

Need for meaning in the face of suffering

Need for integrity, a legacy, generativity

Concerns about relationships: family and/or significant others

Concern or fear about dying or death

Issues related to making decisions about treatment

$\mathrm{R} / \mathrm{S}$ struggle

Other dimensions
The patient is having difficulty coming to terms with changes in things that gave meaning to life (e.g., grief related to key relationships, illness, frailty, dependency).

The patient expresses despair or hopelessness about these changes.

(The focus here is on coming to terms with illness, loss, diminished quality of life, or other diminishment. If the issue is about the meaning of their life, then score under Legacy.)

The patient questions the meaning of life-whether the life he or she has lived has meaning.

Patient has painful regret about some or all of life lived. (If the regret is about a relationship where reconciliation is possible, then score under Concerns about relationships.)

The patient questions whether he or she has made a positive contribution to loved ones, others, or society.

The patient has tasks that must be completed before he or she is ready to die. (If the tasks are interpersonal, score under Concerns about relationships.)

Reminiscing about their life is painful for the patient.

The patient is distressed about having lived an imperfect life. (If the regret, conflict, or discomfort focuses on current illness, score under Need for meaning in the face of suffering.)

The patient has unfinished business with significant others (e.g., need to overcome estrangement, need to express forgiveness, need for reconciliation, and unfulfilled expectations about others).

(Regrets about relationships where reconciliation is unlikely should only be scored under legacy.)

The patient has concerns about the family's ability to cope without him or her.

The patient has concerns that he or she is a burden to family/friends.

The patient expresses isolation or loneliness.

The patient has concerns about dying or being unready for death. This may include explicit hesitation, reluctance, or avoidance to consider or discuss mortality, or associated issues. (This refers to a general sense of unreadiness. If the unreadiness is expressed in terms of specific tasks, score under Need for integrity. If the unreadiness is expressed in terms of unfinished interpersonal tasks, score under Concerns about relationships.)

The patient is impatient for death.

The patient is concerned to participate in important events before death; the patient is concerned that illness or death will prevent participation in important events.

The patient is torn between letting go and fighting on.

The patient has uncertainty or fear about life after death (afraid of damnation; concerned about reunion with loved ones).

The patient has fear of pain or of pain in dying.

The patient needs assistance with value-based advance care planning.

The patient is confused or distressed about end-of-life treatment or about making choices about end-of-life treatment.

The patient wonders whether he or she is being abandoned or punished by God.

The patient is concerned about God's judgment, forgiveness, and/or love.

The patient questions God's love for him or her.

The patient feels God is not answering prayers (e.g., asking to die soon).

The patient expresses anger with God.

The patient is alienated from formerly meaningful connections with religious institutions or leaders.

The patient identifies a need for assistance to perform important rituals, religious or otherwise.

Other spiritual concerns.

R/S, religious/spiritual. 
palliative care near the end of life. The SDAT assigns a score from 0 to 3 representing the chaplain's assessment of the level of the patient's unmet R/S concern or need $(0=$ no evidence of unmet need, $1=$ some evidence of unmet need, $2=$ substantial evidence of unmet need, and $3=$ evidence of severe unmet need) for each of the themes in the spiritual assessment model. The approach to scoring in the SDAT is to limit the score to a patient's explicit expression of R/S concern, need, or distress (e.g., "I feel that I am a burden to my family"). In our work, we found that this focus on explicitly expressed concern was in tension with chaplains' training to be attentive to unexpressed distress or concern. Discussion of this issue led us to create an additional scoring option $0^{*}$. The 0 * score indicates that there is no explicit evidence of $\mathrm{R} / \mathrm{S}$ concern, but the chaplain feels further assessment is needed to confirm this.

The focus on unmet R/S needs or concerns in the SDAT model appears to ignore chaplains' assessment of patients' R/ $\mathrm{S}$ resources as well as their needs. This is not the case; the chaplains' assessment of the patient's R/S resources is taken into account in evaluating the extent to which an R/S concern or need is unmet, that is, beyond the patient's current available personal or interpersonal R/S resources. Thus, a patient who expresses a substantial R/S concern about unfinished business with a family member who also expresses having the ability to reach out and engage that person might be scored 1 (some evidence of unmet need). A patient with a similar concern who, for example, expresses reluctance to reach out and engage the person might receive a score of 2 (substantial evidence of unmet need). In our model, a score of 2 or 3 for any theme implies a level of unmet $\mathrm{R} / \mathrm{S}$ concern or need that should be addressed in a care plan and follow-up care. ${ }^{8,19}$

Our discussions led to several additional clarifications for assigning scores for unmet R/S concerns or needs. First, we assign a score that represents where the patient is at the end of the visit. If there has been change in the level of concern during the visit (decreased or increased), that can be noted in a narrative chart note. Second, prior knowledge of the patient, and especially their ability to cope and other resources available to them, may be used to assign a value for spiritual concerns that have been expressed. Third, where multiple indicators of $\mathrm{R} / \mathrm{S}$ need or concern for one theme are evident, we assign the score for the indicator of greatest need. For example, unfinished business with family or friends and concerns that one is a burden to them are both indicators of potential concerns about relationships. A patient may indicate painful concern about unfinished business with a loved one (scored 3, evidence of severe unmet need) and also wonder if he or she has become a burden to other loved ones (scored 1, some evidence of unmet need). In such a case, the patient would be assessed 3 for concern about relationships.

\section{Spiritual assessment method}

Like the original SDAT, our PC-7 model for spiritual assessment is based on an interview with the patient. The interview is not intended to use structured discussion of the themes or indicators in the model; most chaplains prefer open-ended interviews that are responsive to the patients' concerns. ${ }^{16,28}$ The original SDAT mode ${ }^{28}$ includes interview questions designed to clarify if there are any unmet $R / S$ needs that have not been spontaneously mentioned in the interview.
At present, we have not developed similar questions for the PC-7. When one or more of the themes in the PC-7 have not been mentioned in an open-ended interview, chaplains might comment on them, noting that other patients have had concerns in these areas. The chaplain can then inquire whether they are a concern for the patient being interviewed. While the clinical situation frequently does not allow multiple conversations over several days, when the chaplain has had the opportunity to become more familiar with the patient's background, concerns, and coping resources, our spiritual assessments are likely to be more thorough.

\section{Developing reliability}

A key concern with developing an interviewer rating of the level of R/S concerns or needs is the reliability associated with the model, especially inter-rater reliability. Within our team, inter-rater reliability improved to $100 \%$. Factors associated with our improved inter-rater reliability include the following: clarifying the indicators of R/S concern or need, adding the $0^{*}$ scoring option, and the other scoring clarifications noted above.

Reliability of the PC-7 model was further tested during a national webinar in February 2018, hosted by the Association of Professional Chaplains (APC), in which 154 chaplains participated. In the webinar, after presenting the model, a case vignette was presented and participants used the model to score the spiritual assessment for the case. Table 2 shows the participants' scores for the case (recoded to [0-1] no to some concern vs. [2-3] substantial or severe concern). As can be seen in Table 2, for four of the seven themes, more than $90 \%$ of the participants agreed there was no or some spiritual concern, and for a fifth theme, $84 \%$ of the participants agreed there was substantial or severe concern. We find this a remarkable level of agreement after only a 15-20-minute introduction to the model and the case. We are hopeful that with more extensive training, including practice using the model for spiritual assessment of cases, high levels of inter-rater reliability will be evidenced among chaplains using the model. The Supplementary Data include the case example used in this webinar, the assessments of the case by members of our team, and a brief discussion of those assessments. In addition to this webinar, the model was presented in two workshops attended by 100 chaplains each at the 2017 national conferences of the APC and the National Association of Catholic Chaplains (NACC). The workshops followed a

Table 2. Chaplains' Scores for Siritual Concerns for Webinar Vignette ("Mildred")

\begin{tabular}{lrr}
\hline & \multicolumn{2}{c}{ Scores } \\
\hline Theme & $0-1$ & $2-3$ \\
Need for meaning $(n=117)$ & $92 \%$ & $8 \%$ \\
Need for integrity, a legacy $(n=154)$ & $92 \%$ & $8 \%$ \\
Concerns about family $(n=149)$ & $16 \%$ & $84 \%$ \\
Concern about dying $(n=148)$ & $68 \%$ & $32 \%$ \\
Issues related to treatment decisions $(n=151)$ & $63 \%$ & $37 \%$ \\
R/S struggle $(n=149)$ & $97 \%$ & $3 \%$ \\
Other dimensions $(n=148)$ & $98 \%$ & $2 \%$ \\
\hline
\end{tabular}

Scores are dichotomized: $0-1=$ no or some spiritual concern; $2-$ $3=$ substantial or severe spiritual concern. 
format similar to the webinar with similar levels of reliability for scoring the case vignettes that were presented. The workshop participants also expressed enthusiasm for having a quantifiable model for assessment specific to patients receiving palliative care near the end of life.

\section{Discussion}

A key concern in developing a model for spiritual assessment in palliative care is whether the model encompasses the R/S needs or concerns that are encountered most frequently in this clinical context; that is, does the model have face validity? Our evidence for the face validity of the PC-7 model comes from three sources. The first source is the consistency of the themes in the model with existing theoretical and empirical literature about spiritual issues at the end of life. ${ }^{30,31}$ The second source is the use of case examples taken from the clinical practice of the team members to inform the development of the key themes in the model. The third source is the positive response to the PC-7 model from colleagues who have participated in the workshops and webinar where it has been presented. Discussions in these sessions did not identify any major themes that were missing from the model.

Limitations of the PC-7 model include those we have previously noted. While the focus of palliative care is addressing the needs of patients with serious illness, our model is limited to palliative care patients who are facing the end of life. In addition, palliative care, as well as spiritual care within palliative care, seeks to address the needs of both patient and loved ones, while our model focuses only on the $\mathrm{R} / \mathrm{S}$ needs of the patient. We felt these limitations provided necessary focus for the development of this new approach to spiritual assessment in palliative care. We hope future work will address them. Colleagues have also noted that the theistic assumptions in the indicators for R/S struggle may limit the validity of the theme for nontheistic patients. These indicators were drawn from the items in the negative religious coping subscale of the Brief RCOPE. ${ }^{23}$ Until recently, this has been the most widely used measure of R/S struggle among patients with diverse conditions. ${ }^{25}$ For example, among patients with advanced illness, higher levels of R/S struggle have been associated with poorer quality of life. ${ }^{32}$ Revisions to these indicators should be considered in future research especially in light of new measures of R/S struggle ${ }^{33}$ and spiritual pain ${ }^{24}$ that have been reported.

The PC-7 model requires further testing for reliability and validity; the work of Monod and colleagues ${ }^{15}$ examining the reliability and validity of the SDAT provides a model for this research. Research is needed that examines the validity and reliability of the PC-7 model in culturally diverse samples, including those from non-Christian faiths and those who have no religious affiliation. The PC-7 model was developed based on hospitalized patients; research is also needed about its validity and reliability in outpatient, home care, and hospice contexts. Furthermore, while the PC-7 model has been enthusiastically received by chaplaincy colleagues, systematic research is needed into chaplains' experience and comfort using the model. In addition, research is needed to determine whether palliative care colleagues in other disciplines (physicians, nurses, and social workers) find the model provides them with the information they need about the patient's R/S needs and concerns and provides it in an efficient way. ${ }^{34}$ Once proven reliable and valid, the PC-7 model can be used to identify the prevalence and intensity of unmet R/S needs and concerns among patients at the end of life and in research testing the effects of spiritual care interventions that address those needs.

\section{Conclusion}

After reviewing chaplain documentation of care for patients in the ICU, Aslakson and colleagues ${ }^{3(\mathrm{p} 654)}$ recommended that the profession "explore ways of having more explicit and standardized documentation of spiritual assessment content in both chaplain and/or palliative care notes." Here, we report the development of the PC-7, an evidence-based model for spiritual assessment in palliative care that addresses these recommendations and other limitations of current approaches to spiritual assessment, such as their one-size-fits-all approach and narrative method.

\section{Acknowledgments}

We express our thanks to the Coleman Foundation for their support of the Coleman Palliative Medicine Training Program (https://colemanpalliative.uchicago.edu/), which brought our team together and enabled our initial work on this model for spiritual assessment in palliative care. We also acknowledge our gratitude for the assistance of Kristen Schenk in preparing the article for publication.

\section{Funding Information}

This research did not receive any specific grant from funding agencies in the public, commercial, or not-for-profit sectors.

\section{Author Disclosure Statement}

No competing financial interests exist.

\section{Supplementary Material}

Supplementary Data

\section{References}

1. National Consensus Project for Quality Palliative Care: Clinical Practice Guidelines for Quality Palliative Care, 4th ed. Richmond, VA: National Coalition for Hospice and Palliative Care, 2018.

2. Puchalski C, Ferrell B, Virani R, et al.: Improving the quality of spiritual care as a dimension of palliative care: The report of the Consensus Conference. J Palliat Med 2009;12:885-904.

3. Aslakson RA, Kweku J, Kinnison M, et al.: Operationalizing the measuring what matters spirituality quality metric in a population of hospitalized, critically ill patients and their family members. J Pain Symptom Manage 2017; 53:650-655.

4. Johnson R, Wirpsa MJ, Boyken L, et al.: Communicating chaplains' care: Narrative documentation in a neurosciencespine intensive care unit. J Health Care Chaplain 2016;22: $133-150$. 
5. Lee BM, Curlin FA, Choi PJ: Documenting presence: A descriptive study of chaplain notes in the intensive care unit. Palliat Support Care 2017;15:190-196.

6. Balboni TA, Fitchett G, Handzo GF, et al.: State of the science of spirituality and palliative care research Part II: Screening, assessment, and interventions. J Pain Symptom Manage 2017;54:441-453.

7. Fitchett G: Assessing Spiritual Needs: A Guide for Caregivers. Lima, OH: Academic Renewal Press, 2002.

8. Lucas AM: Introduction to the discipline for pastoral care giving. In: VandeCreek L, Lucas AM (eds): The Discipline for Pastoral Care Giving. Binghamton, NY: Haworth Press, Inc., 2001, pp. 1-33.

9. Pruyser PW: The Minister as Diagnostician. Philadelphia: Westminster Press, 1976.

10. Shields M, Kestenbaum A, Dunn LB: Spiritual AIM and the work of the chaplain: A model for assessing spiritual needs and outcomes in relationship. Palliat Support Care 2015;13: 75-89.

11. Canada AL, Fitchett G: Religion/spirituality and cancer: A brief update of selected research. In: Holland JC, Breitbart WS, Butow PN, et al. (eds): Psycho-Oncology, 3nd ed. New York: Oxford University Press, 2015, pp. 503-508.

12. Peteet JR, Balboni MJ: Spirituality and religion in oncology. CA Cancer J Clin 2013;63:280-289.

13. Lewis JM: Pastoral assessment in hospital ministry: A conversational approach. Chaplaincy Today 2002;18: 5-13.

14. Handzo GF, Cobb M, Holmes C, et al:: Outcomes for professional health care chaplaincy: An international call to action. J Health Care Chaplain 2014;20:43-53.

15. Monod S, Martin E, Spencer B, et al. Validation of the spiritual distress assessment tool in older hospitalized patients. BMC Geriatr 2012;12:13.

16. O'Connor TS, Meakes E, O'Neill K, et al.: Not well known, used little and needed: Canadian chaplains' experiences of published spiritual assessment tools. J Pastoral Care Counsel 2005;59:97-107.

17. Levine S, O'Mahony S, Baron A, et al.: Training the workforce: Description of a longitudinal interdisciplinary education and mentoring program in palliative care. J Pain Symptom Manage 2017;53:728-737.

18. Jeuland J, Fitchett G, Schulman-Green D, Kapo J: Chaplains working in palliative care: Who they are and what they do. $\mathrm{J}$ Palliat Med 2017;20:502-508.

19. Massey K, Barnes MJ, Villines D, et al.: What do I do? Developing a taxonomy of chaplaincy activities and interventions for spiritual care in intensive care unit palliative care. BMC Palliat Care 2015;14:10.

20. Steinhauser KE, Clipp EC, McNeilly M, et al.: In search of a good death: Observations of patients, families, and providers. Ann Intern Med 2000;132:825-832.
21. Steinhauser KE, Bosworth HB, Clipp EC, et al.: Initial assessment of a new instrument to measure quality of life at the end of life. J Palliat Med 2002;5:829-841.

22. Steinhauser KE, Clipp EC, Bosworth HB, et al.: Measuring quality of life at the end of life: Validation of the QUAL-E. Palliat Support Care 2004;2:3-14.

23. Pargament KI, Smith BW, Koenig HG, et al.: Patterns of positive and negative religious coping with major life stressors. J Sci Study Relig 1998;37:710-724.

24. Delgado-Guay MO, Chisholm G, Williams J, et al.: Frequency, intensity, and correlates of spiritual pain in advanced cancer patients assessed in a supportive/palliative care clinic. Palliat Support Care 2016;14:341-348.

25. Exline JJ: Religious and spiritual struggles. In: Pargament KI, Exline JJ, Jones J (eds): APA Handbook of Psychology, Religion, and Spirituality (Vol 1). Washington, DC: American Psychological Association Press, 2013, pp. 459-475.

26. Erikson EH, Erikson JM: The Life Cycle Completed: Extended Version with New Chapters on the Ninth Stage of Development. New York: W W Norton \& Co., 1997.

27. MacKinlay EB, Trevitt C: Spiritual care and ageing in a secular society. Med J Aust 2007;186:S74-S76.

28. Monod S, Rochat E, Bula C, Spencer B: The spiritual needs model: Spirituality assessment in the geriatric hospital setting. J Relig Spiritual Aging 2010;22:271-282.

29. Monod SM, Rochat E, Büla CJ, et al.: The spiritual distress assessment tool: An instrument to assess spiritual distress in hospitalised elderly persons. BMC Geriatr 2010;10:88.

30. Benito E, Oliver A, Galiana L, et al.: Development and validation of a new tool for the assessment and spiritual care of palliative care patients. J Pain Symptom Manage 2014;47: 1008-1018.e1.

31. Leget C: Art of Living, Art of Dying: Spiritual Care for a Good Death. London: Jessica Kingsley Publishers, 2017.

32. Tarakeshwar N, Vanderwerker LC, Paulk E, et al.: Religious coping is associated with quality of life of patients with advanced cancer. J Palliat Med 2006;9:646-657.

33. Exline JJ, Pargament KI, Grubbs JB, et al:: The religious and spiritual struggles scale: Development and initial validation. Psychol Relig Spiritual 2014;6:208-222.

34. Choi PJ, Chow V, Curlin FA, Cox CE: Intensive care clinicians' views on the role of chaplains. J Health Care Chaplain 2018;5:1-10.

Address correspondence to: George Fitchett, DMin, PhD Department of Religion, Health, and Human Values Rush University Medical Center 1653 West Congress Parkway Chicago, IL 60612

E-mail: george_fitchett@rush.edu 